\title{
11. Variation in the Early and Middle Pleistocene: The phylogenetic relationships of Ceprano, Bodo, Daka, Kabwe and Buia
}

\author{
Debbie Argue
}

\section{Introduction}

Despite the increased number of hominin fossils available for the period from one million years ago to c.600 ka clarity about their phylogenetic relationships has not emerged. This is because, while studies of each of these hominins typically include comparative analyses with similar fossil material, in most cases this has resulted in controversy as to their affinities and phylogenetic relationships. Variation during this period is explained by some as representing a single species, $H$. erectus. For others it represents multiple taxa among which $H$. erectus is an exclusively Asian species; or a modified version of this in which observed variation is viewed as continual remodelling of the vault and face that does not involve speciation events (Mbua and Bräuer, 2012). As well, the morphological boundaries of $H$. erectus continue to be stretched. Asfaw and others (2002) referred the Daka cranium (Middle Awash, Ethiopia dated c.800 ka years ago) to $H$. erectus despite clear differences in cranial characters from $H$. erectus s.S., and concluded from cladistic analyses that its morphology is consistent with the hypothesis of a widespread polymorphic and polytypic species existing one million years ago representing a single evolving lineage series of Homo erectus fossils in Africa. Ascenzi and others (1996) referred the Ceprano cranium (Italy), at the time thought to be c. 800 ka but recently dated to c. $450 \mathrm{ka}$ (Muttoni et al., 2009), to $H$. erectus while acknowledging differences from $H$. erectus s.s. such as a larger endocranial volume, no sagittal keel or parasagittal depression. Bodo (600 ka) and Kabwe (date unknown) from Africa are viewed as more derived than Early Pleistocene Homo. Kabwe has been placed in a separate species, $H$. rhodesiensis, or as a subspecies of $H$. sapiens, $H$. sapiens rhodesiensis, in recognition of some perceived relatively modern characters; and Bodo has also been placed in $H$. sapiens rhodesiensis.

There are two other hominins known from this period. The Buia cranium from Eritrea (Abbate et al., 1998) dated to 992 ka (Albianelli and Napoleone, 2004) has not been fully described and was unavailable for study at the time this 
research was undertaken. There are, however, morphological descriptions from which similarities and differences with its contemporaries, Ceprano, Daka, Kabwe and Bodo, may be observed. Secondly, ATD6-69 (partial face) and the frontal (ATD6-15) from the same individual, a child, from Gran Dolina, Spain dating to 780-857 ka (Falguèrès et al., 1999) has been placed in a new species, Homo antecessor (Bermúdez de Castro et al., 1997). Few of the characters used in the present study are available for this hominin. It proved quite unstable in the phylogenetic analyses I performed earlier (Argue, 2010) and its relationships indeterminable. I, therefore, do not include it in these analyses.

I use cladistic analyses incorporating Early and Middle Pleistocene fossil crania from Africa and Asia to test existing hypotheses about the phylogenetic relationships of Ceprano, Daka, Kabwe and Bodo to propose an alternative hypothesis for human evolution during the period c.1 Ma-600 ka.

\section{Background}

\section{Daka}

The Daka cranium, BOU-VP-2/66, (Ethiopia), was found in situ in sediments with a basal 40Ar/39Ar age of $1.042 \pm 0.009 \mathrm{Ma}$; the sediments are reverse polarity and their minimum age is therefore estimated to be c.0.8 Ma (Asfaw et al., 2002). The cranium is well preserved although it has some distortion. Its discoverers concluded from cladistic analyses that it is Homo erectus (Asfaw et al., 2002). Manzi and others (2003), however, using a phenetic approach which quantifies overall similarity of single specimens, found that Daka shares the greatest affinities with two fossil specimens from the Koobi Fora region in Africa, KNM-ER 3733 and KNM-ER 3883, which they attributed to H. ergaster, and that Daka is very different from $H$. erectus. They proposed that Daka is best viewed as part of a local African evolutionary lineage spanning 1.8 Ma-c.1 Ma.

\section{Ceprano}

Many fragments of a cranium were found near the town of Ceprano, Italy, in 1994 (Ascenzi et al., 1996). Originally dated to $>700 \mathrm{ka}$ (Ascenzi et al., 1996), further studies have proposed two younger dates. Muttoni and others (2009) and Manzi and others (2010) report that the level that yielded the hominin cranium has an age of c.0.45 Ma; while a date of $0.35 \pm 4$ Ma (Nomade et al., 2011) based on 40Ar/39Ar dating on K-feldspars retrieved from the sediments that hosted the skull has also been proposed. 
Ceprano was at first referred to $H$. erectus, particularly to late $H$. erectus, by which Ascenzi and others (1996) were referring to the Middle Pleistocene fossils Arago, Petralona, and contemporaries which, as they acknowledge, some would attribute to $H$. heidelbergensis. Clarke (2000) undertook a reconstruction of the cranium during 1997 which resulted in a revision of its reported metric values. Although these changes altered a number of characteristics of the cranium, Clarke (2000) retained it in $H$. erectus; this was supported by Ascenzi and others (2000) based upon their comparison of the character states observed on Ceprano with the distinctive features of $H$. erectus listed by Wood (1991: Table 2.11, p.37). Manzi and others (2001), after declaring their confidence in the new reconstruction, calculated phenetic distances using two methods (Unweighted pair group method (UPGMA); Neighbour Joining (NJ)) to generate unrooted phylogenetic trees. The UPGMA method yielded a tree in which Ceprano is grouped with the African Middle Pleistocene sample (Kabwe, Bodo, Saldhana) and the NJ tree shows Ceprano in an isolated position but nevertheless closer to the African Middle Pleistocene group than to Sangiran (Indonesian) and Zhoukoudian (China) H. erectus, Dmanisi, and other Early Pleistocene African crania. Mallegni and others (2003) performed a cladistic analysis using 30 cranial characters yielding eight equally parsimonious trees from which a strict-consensus tree showed Ceprano and Daka in a monophyletic (sister taxa) group with $84 \%$ bootstrap support although they found only one unambiguous synapomorphy (short cranial vault) and one ambiguous synapomorphy (presence of sharply angulated occipital profile) for the clade. They proposed a new species for Ceprano, $H$. cepranensis sp. nov., based upon their assessment that it possesses a unique suite of characters, Beyond a brief discussion of shared characters, they did not engage in a discussion of the apparent close relationship of Ceprano and Daka.

Ceprano, then, has been referred to 'late H. erectus' ( $=H$. heidelbergensis)(Ascenzi et al., 1996); H. erectus (Clarke, 2000; Ascenzi et al., 2000), and specifically not $H$. heidelbergensis (Clarke, 2000); a new species H. cepranensis sp. nov. (Mallegni et al., 2003); and, possibly, H. heidelbergensis (Manzi et al., 2001).

\section{Bodo}

Bodo is a partial cranium (Bodo d'Ar, Ethiopia) estimated to be $600 \mathrm{ka}$ based on biostratigraphic and archaeological considerations (Clarke et al., 1994). In their original announcement, Conroy and others (1976) refrained from making a taxonomic determination. Later, Kalb and others (1982) assigned Bodo to $H$. sapiens rhodesiensis, including it in a taxon with Kabwe (H. rhodesiensis; Smith Woodward, 1921); Stringer (1984) conditionally compared Bodo to H. erectus s.s., although he recognised the possible phylogenetic significance of some $H$. sapiens features of this cranium; Groves (1989) attributed Bodo to a subspecies 
of H. sapiens, as did Adefris (1992) in his dissertation on this fossil (although he preferred the term 'archaic Homo sapiens'); Rightmire (1996) undertook a detailed description and comparative analysis of the Bodo cranium, concluding that it seems most reasonable to group it with Kabwe and similar specimens from the Middle Pleistocene sites in Africa and Europe.

\section{Kabwe}

Kabwe 1 was found during mining operations in the basal wall of a steeply sloping cleft emanating from a cave within a small hillock at Broken Hill, Zimbabwe (then Rhodesia). It has not been dated, and, as it seems to have rolled down the cleft at an unknown time, and was annually inundated by a high water table (Hrdlicka, 1930), so attempts to date it, particularly by using the Electron Spin Resonance method, would be compromised. Further, the hillock no longer exists, having been completely mined. It has not, then, been possible to reliably estimate Kabwe's age. It was originally attributed to a new species, $H$. rhodesiensis by Smith Woodward (1921) who viewed it as quite different from $H$. neanderthalensis and $H$. erectus. Having compared the Broken Hill skull to those of $H$. neanderthalensis, Omo I and II, Hopefield, and OH 9, Rightmire (1976) gave Kabwe a subspecific designation $H$. sapiens rhodesiensis that probably evolved from local groups of $H$. erectus.

Bräuer (1984) assigned Kabwe to 'early archaic $H$. sapiens' ${ }^{1}$ in a group that included Bodo, Hopefield, Eyasi, Ndutu and other African crania, as the cranial vaults are more expanded than $H$. erectus. Groves (1989) placed Kabwe in a subspecies of $H$. sapiens, $H$. sapiens heidelbergensis, that includes the African and European Middle Pleistocene fossils; Kabwe, Bodo, Tighenif and later fossils from Europe and Africa.

Daka, Ceprano, Bodo and Kabwe are, then, each variously attributed to a range of species. The objective is to resolve the phylogenetic position of each so that we may generate hypotheses concerning human evolution during his period.

\section{Materials and methods}

Information about cranial characteristics was obtained from original fossil material and casts of Early and Middle Pleistocene Homo so that cladistic analyses could be performed.

1 The term 'early archaic H. sapiens' is now considered unsatisfactory, being a descriptive category rather than a taxonomic term, and has been generally replaced with $\mathrm{H}$. heidelbergensis; the taxon is considered to comprise similar hominins from Africa and Europe. 
The comparative sample comprises:

- Sangiran 2, 4, 9, 17 and Trinil (H. erectus);

- KNM-ER 1813, OH 24 (Homo habilis; casts);

- KNM-ER 3733;

- KNM-ER 3883;

- Daka;

- Ceprano;

- Bodo; and

- Kabwe (H. rhodesiensis).

I compiled 89 cranial character states (Appendix 1) of which 62 are phylogenetically informative for this set of OTUs (Operational Taxonomic Units). Character states are derived from Lahr (1996), and Schwartz and Tattersall (2002); and Zeitoun (2000) who referred to Weidenreich (1943), MacIntosh and Larnach (1972), Sartono and Grimaud (1983), Grimaud (1982), and Hublin (1978).

Cladistic analysis is widely used in the biological sciences as a methodological approach to phylogenetic reconstruction and has been applied to hominin taxa since the 1970s. It assumes that shared features observed among taxa can be explained by hypotheses of common ancestry that are represented by sets of characters in a hierarchical pattern of taxa (Faith and Cranston, 1991) and is based upon Hennig's (1966) approach to systematics, specifically his approach to descent with modification. Descendants acquire traits transmitted genetically from their ancestors and these are passed on to subsequent descendants (Humphries, 2002). The aim of cladistic analysis is to identify taxa that share a common ancestor by finding, or distinguishing, shared derived character states (synapomorphies) from among the characters in the data set. Cladistic analysis produces possible phylogenetic trees, called cladograms, which are branching diagrams that depict sister group relationships. The cladogram groups OTUs into clusters called clades, and these represent hypotheses about relationships among OTUs. Cladistic analysis is based upon the total number of character changes necessary to support the relationship of OTUs in a tree. The shortest trees are those that account for the observed differences among taxa in the smallest number of evolutionary steps. They are the most parsimonious trees and are generally considered to present the best working hypotheses (after Argue et al., 2009). The phylogenetic trees presented here are derived from my data and analyses.

Before performing a cladistic analysis it seems useful to assess the probability that the phylogenetic trees derived from the data could have arisen by chance alone (Faith, 1991). To test for this I performed a Permutation Tail Probability Test (PTP) in which a ' $\mathrm{p}$ ' value of 0.05 or less would indicate that the null 
hypothesis, that the data are random, is rejected while noting that the meaning of a ' $\mathrm{p}$ ' value of $>0.05$ is controversial (Carpenter et al., 1998; Källersjö et al., 1992; Trueman, 1993; Fu and Murphy, 1999). For this data and taxon set, the PTP value (excluding the outgroup) is $\mathrm{p}=0.01$ and I consider that these data therefore represent a non-random tree structure.

I perform a heuristic search of the cranial data using PAUP* (Phylogenetic Analysis Using Parsimony) Version 4.0b10 for Macintosh (Swofford, 2002), to find the most parsimonious tree or trees. I examine the relative strength of the clades identified by using 1,000 replications of the PAUP bootstrap test. The bootstrap analysis begins by creating a number of pseudo replicate data matrices from the original dataset by resampling the original data matrix and creating a matrix of the same size as the original. Any data series might be represented in any pseudo matrix once, twice, many times, or none at all. The frequency at which a set of clades appear in these reiterations constitutes the bootstrap score. If a particular clade has a high number of characters supporting it, and few characters refuting its monophyly, the chances are that at least some of these will appear in the resampling process and the group will appear in many of the trees generated. If evidence for the monophyly is weak or there is a high level of homoplasy (similar character state in more than one taxon derived from mechanisms other than immediate shared ancestry) in the original matrix, the group might not appear at all, or at low frequency; and the probabilities obtained are not the probability of the reality of clades as such, but reflect the relative support of the clades, given the assumptions in the technique (Wiley and Liebermann, 2011).

The most parsimonious trees found in the initial PAUP search are transposed into MacClade (Maddison and Maddison, 1982). MacClade provides an interactive environment for exploring phylogeny and was developed to help biologists explore relationships between OTUs (Maddison and Maddison, 1982). In MacClade's tree window, phylogenetic trees (cladograms) can be manipulated and alternative hypotheses for an individual taxon, or groups of taxa, may be explored. I, therefore, reproduce the shortest tree produced in the initial analysis (that used PAUP*) in MacClade so that I can test hypotheses that have been presented for each OTU by constraining relevant OTUs and comparing the ensuing tree lengths with the length of the shortest tree. I can test, for example, the likelihood that Daka shared a common ancestor with Ceprano or H. erectus; or if Kabwe and Bodo likely shared a common ancestor.

Clades are further tested using a topology-dependent permutation tail probability test (T-PTP); this tests the support for clades, or sister taxa, shown in the cladogram (Faith and Cranston, 1991; Faith, 1991). The test is defined as the estimate of the proportion of times that a given clade can be found, generated from permuted data that are as short as, or shorter than, the original 
tree. That is, it compares the degree of corroboration for the observed data to that expected by chance alone, so is a test of monophyly of selected nodes. I reject the null hypothesis, that the data have no cladistic structure beyond that produced by chance, at the 0.05 level if fewer than five out of 100 of the trees have a length as short, or shorter, than the cladogram, that is, if the T-PTP result is $\geq 0.05$.

\section{Results}

\section{Shortest trees}

There are three shortest trees 245 steps long (Figure 11.1). In each case, Daka, Ceprano and Bodo form a branch but its configuration varies; in one tree these OTUs form a branch with $H$. rhodesiensis (Tree 3).

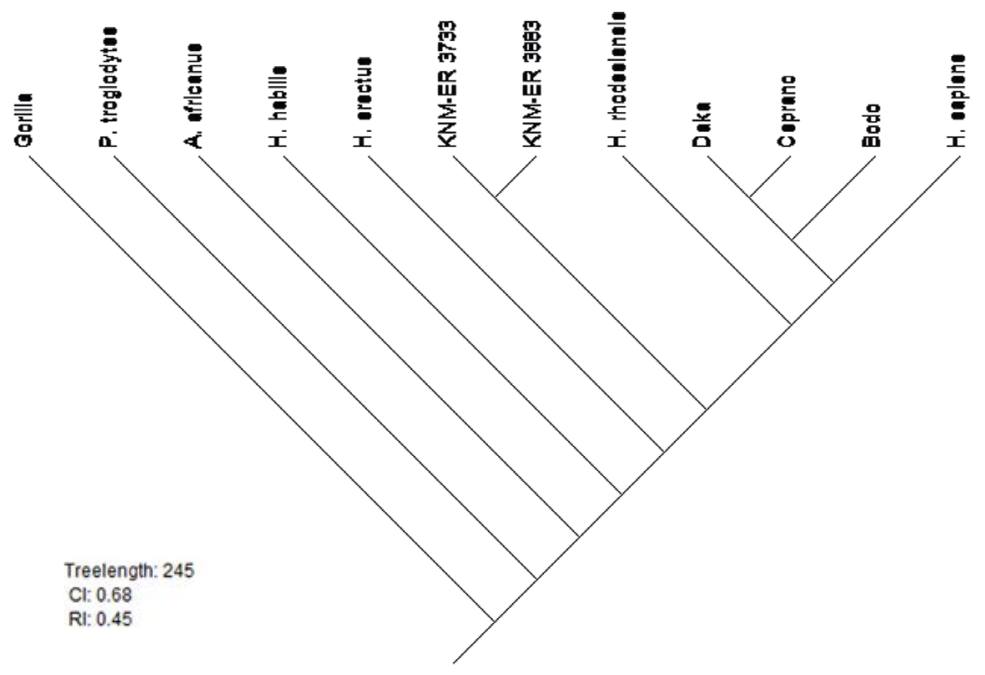

Figure 11.1a: Three shortest trees.

Source: Author's calculations. 


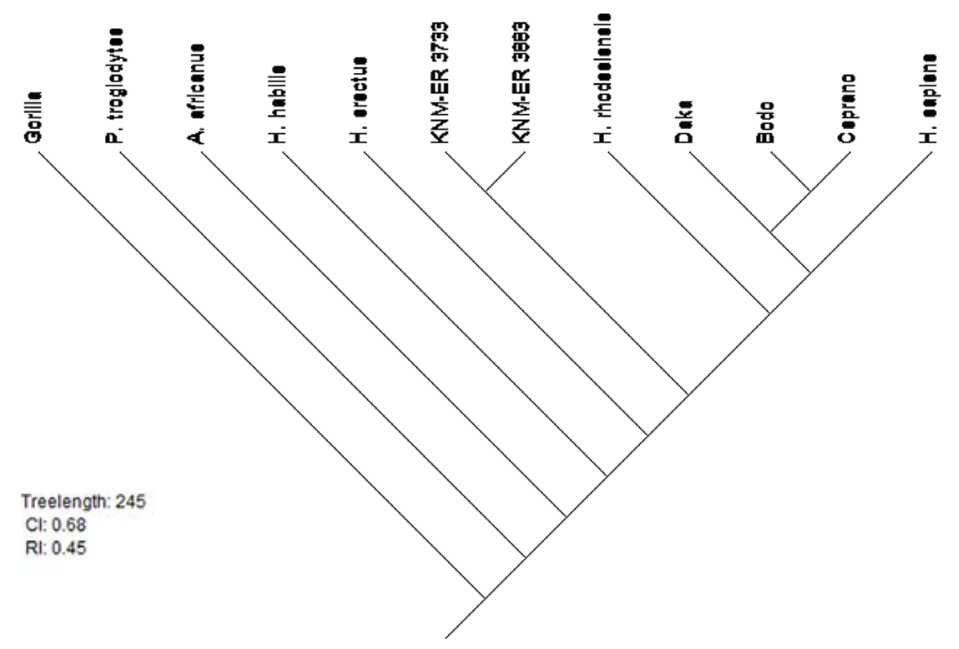

Figure 11.1b: Three shortest trees.

Source: Author's calculations.

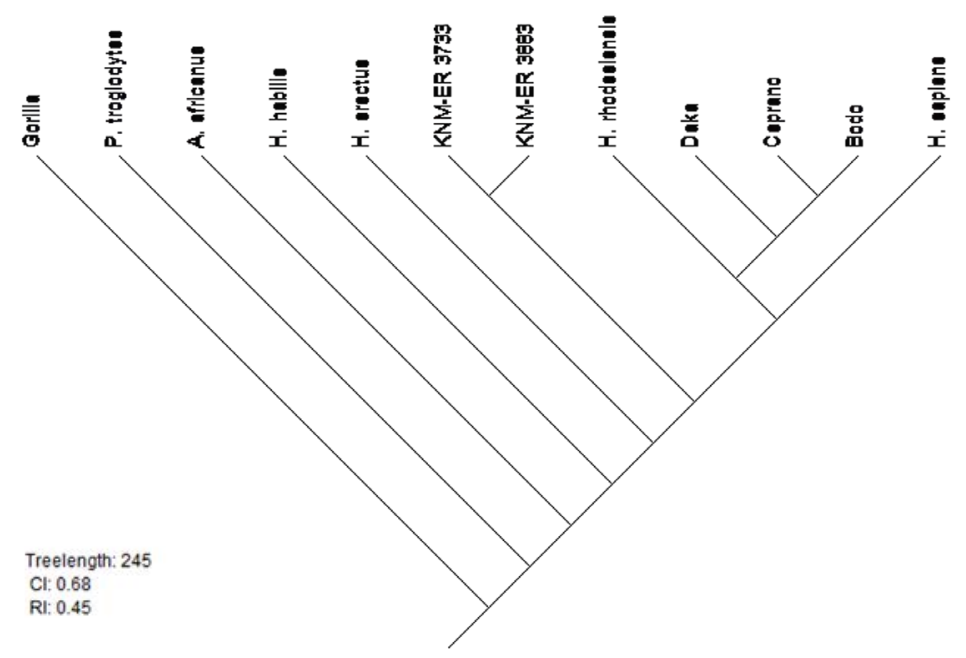

Figure 11.1c: Three shortest trees.

Source: Author's calculations. 


\section{Bootstrap analysis}

The bootstrap analysis (Figure 11.2) shows two clades with $>50 \%$ support. The value for the clade comprising Bodo and Ceprano is 54\%; for the Koobi Fora group it is $61 \%$. Neither of these results reaches the threshold of $70 \%$ (Hillis and Bull, 1993). This would suggest that either there is a high level of homoplasy in the data or evidence for the clades is not strong (or both). The Consistency Index (CI) for these data is 0.68 where a value of 1.0 indicates that there is no homoplasy. This CI suggests that there is indeed likely to be homoplasy in these data but one might also suppose that the support for the clades is not particularly strong.

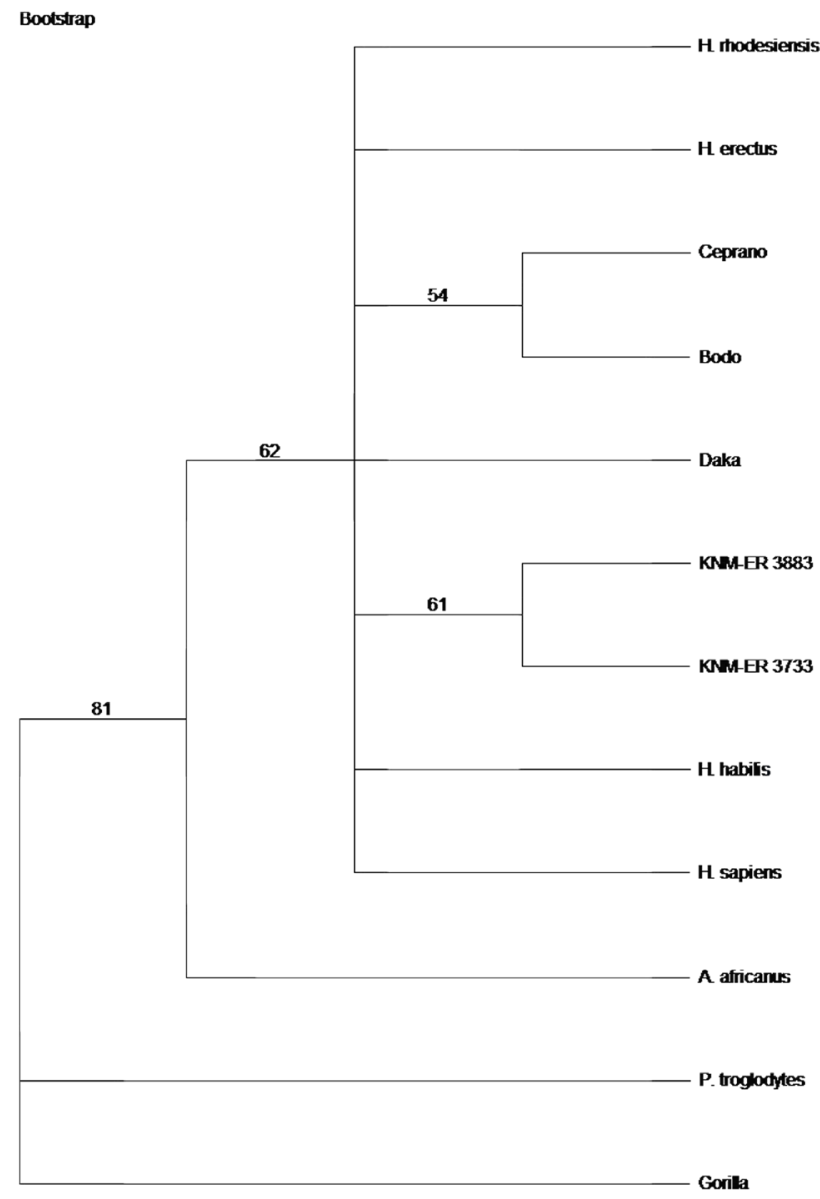

Figure 11.2: Bootstrap analysis.

Source: Author's calculations. 
I had earlier tested our data for randomness using the PTP test (above), which led me to conclude that the data is not random and represents phylogenetic structure. I, therefore, am satisfied that the results provide a valid basis upon which to test hypotheses and I treat the clades as representing phylogenetic relationships. Nevertheless I test for the likelihood that each clade on the shortest tree is monophyletic as opposed to occurring by chance alone.

\section{Testing clades and branches}

\section{Bodo, Daka and Ceprano}

As Bodo and Ceprano form a clade in two of the shortest trees I test the likelihood that this apparent sister taxon relationship occurred by chance alone. The T-PTP result is $\mathrm{p}=0.04$ indicating that Bodo and Ceprano do not group by chance alone.

The clade shares four possible ${ }^{2}$ synapomorphies:

- Post-orbital lateral depression (a depression on the lateral supraorbital region bounded by the temporal line)

- Weak metopic keeling

- Anteroposterior width of mandibular fossa is narrow

- The posterior edge of the tuberculum articular in norma basilaris is arched.

In another of the shortest trees, Ceprano and Daka form sister taxa. The T-PTP for the clade is, however, $\mathrm{p}=0.19$. This would suggest that this clade would come together by chance alone. In fact, the clade shares only two possible synapomorphies: the articular eminence is higher relative to posterior wall of glenoid fossa; and each has an angular torus. In comparison, Mallegni and others' (2003) analysis shows a strongly supported (84\%) Daka-Ceprano clade, notwithstanding that the OTUs share only two synapomorphies: a short cranial vault; and the presence of a sharply angled occipital profile. Based upon our T-PTP result, we would reject Tree 1 (Figure 11.1) as the most parsimonious solution to the data.

The monophyly for Ceprano, Bodo and Daka, however, is not rejected; the T-PTP is $p=0.04$; that is, it is unlikely that this clade would form by chance alone. If we accept the T-PTP result above for Ceprano and Daka, rejecting it as a viable clade within the branch, the most parsimonious solution is that Bodo and Ceprano are sister taxa; and Daka shares a common ancestor with each of them. Ceprano, Bodo and Daka share the following five possible synapomorphies:

2 A particular character state might occur in taxa that are not included in this analysis, so we cannot say categorically that a given state is uniquely synapomorphic for the sister taxa in this study. 
- The frontal edge is convex anteriorly in norma verticalis

- The supraorbital torus is interrupted in the medial zone, forming two 'mono-tori'

- Temporal squama low in relation to vault

- Posterior part of tympanic joins anterior part of mastoid process

- Postglenoid process does not extend laterally beyond extent of tympanic.

\section{Daka, Ceprano, Bodo, H. rhodesiensis}

The T-PTP for the branch comprising Bodo, Ceprano, Daka and H. rhodesiensis is also $\mathrm{p}=0.04$. It shares five synapomorphies:

- Depression at glabella

- Angulation between the pre-glenoid planum and the posterior slope of the articular tuberculum (homoplasy with $A$. africanus)

- The supraorbital margin is thick, rounded and not demarcated from the roof of the orbit

- A pre-glenoid planum precedes the glenoid cavity (homoplasy with $A$. africanus and $H$. erectus)

- A very prominent temporal band on the frontal (homoplasy with the two Koobi Fora hominins).

Before presenting hypotheses for human evolution during this period I test hypotheses previously presented for Daka, Bodo, and Ceprano. In this case, I use the phylogeny in Tree 3 (Figure 11.1) in which Bodo, Ceprano and Daka are on a branch with $H$. rhodesiensis, as the analyses so far would suggest that this is the most parsimonious solution to the data.

\section{Testing other hypotheses for OTUs}

\section{Bodo}

Bodo has been named $H$. sapiens rhodesiensis (Kalb et al., 1982); a subspecies of H. sapiens (Groves, 1989; Adefris, 1992) and, conditionally, H. erectus (Stringer, 1984). The shortest trees in this analysis show Bodo on a branch with, amongst others, $H$. rhodesiensis.

\section{Bodo and $H$. rhodesiensis}

To argue $H$. rhodesiensis subspecies status for Bodo we would expect the tree in which these OTUs are constrained to be as short, or nearly so, as the shortest tree for this set of OTUs. When Bodo is constrained to form a clade with $H$. rhodesiensis, however, the shortest trees length is 253 steps (Figure 11.3). This is 
eight steps longer than the shortest tree $(\mathrm{L}=245)$; and the CI has decreased to 0.66. Such a tree, then, is a less parsimonious explanation of the data. Bodo is unlikely to be a subspecies of $H$. rhodesiensis.

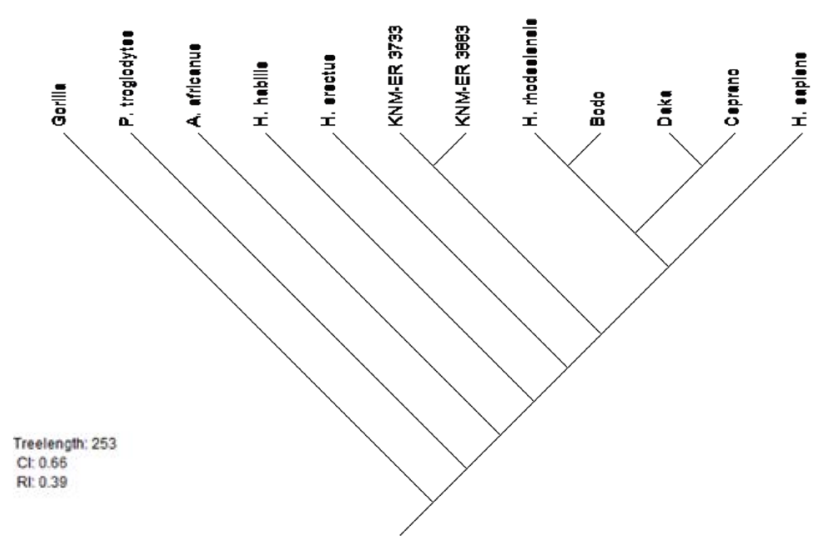

Figure 11.3: Bodo and $\boldsymbol{H}$. rhodesiensis.

Source: Author's calculations.

Bodo and $H$. erectus

The shortest tree in which Bodo and $H$. erectus are constrained to form a clade is $\mathrm{L}=249$ (Figure 11.4), four steps longer than the shortest tree $(\mathrm{L}=245)$ for Bodo. The T-PTP for the constrained clade is $\mathrm{p}=0.18$. This is, therefore, also an unlikely solution for Bodo.

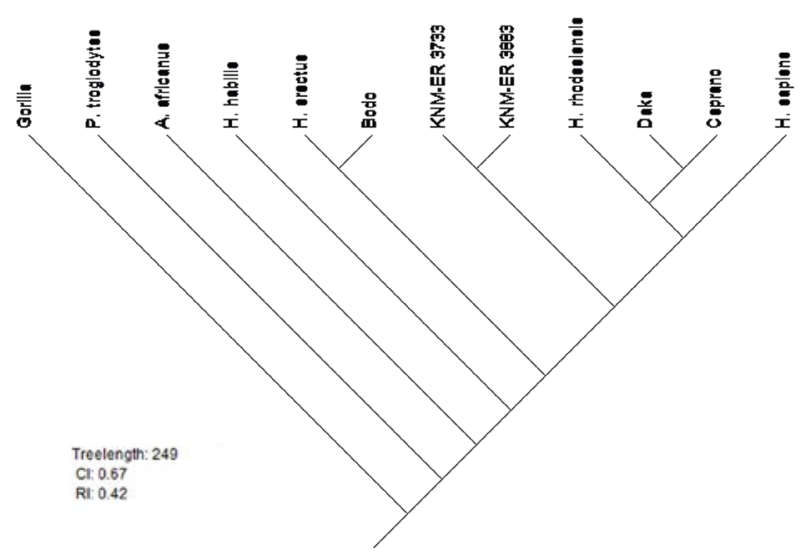

Figure 11.4: Bodo and $\boldsymbol{H}$. erectus.

Source: Author's calculations. 


\section{Daka}

\section{Daka and $H$. erectus}

Asfaw and others (2002) proposed that Daka is H. erectus. When this hypothesis is tested in the present study by constraining Daka to form a clade with $H$. erectus the shortest tree length is 251 (Figure 11.5); this is six steps longer than the most parsimonious tree $(\mathrm{L}=245)$, and the T-PTP is $\mathrm{p}=0.27$; a phylogeny in which Daka and $H$. erectus form sister taxa is a less parsimonious solution for Daka than that identified in the shortest trees.

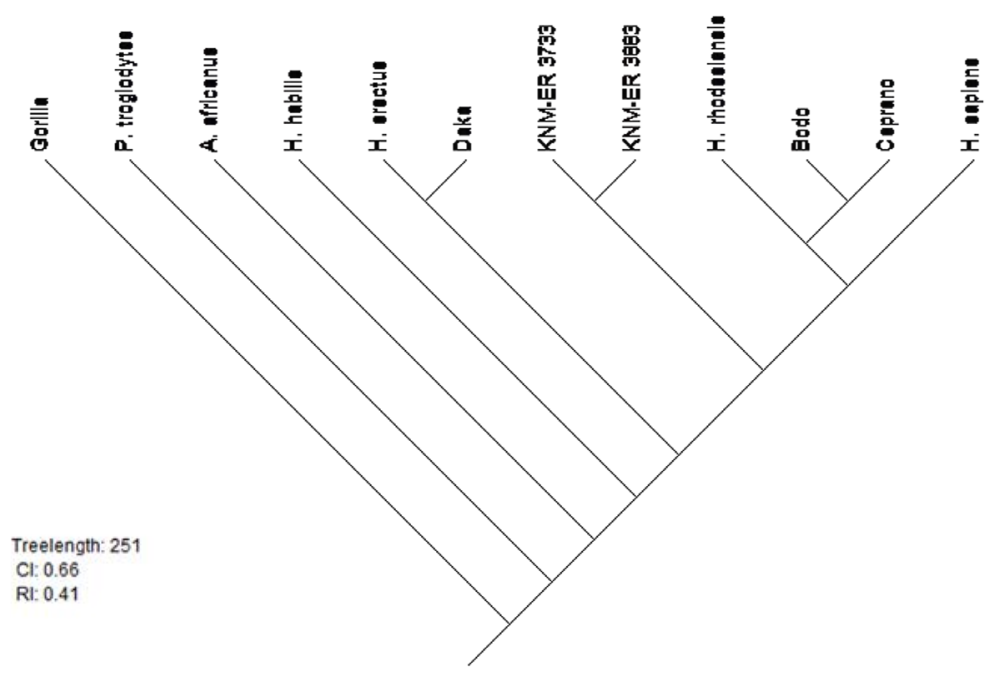

Figure 11.5: Daka and $\boldsymbol{H}$. erectus.

Source: Author's calculations.

\section{Daka and KNM-ER 3733 and KNM-ER 3883}

I explore the possibility for a chronological and anatomical morphocline from the Koobi Fora hominins KNM-ER 3733 and KNM-ER 3883 to Daka/Buia as proposed by Asfaw and others (2002) by testing if it is possible that Daka shared an immediate common ancestor with KNM-ER 3733 and KNM-ER 3883. The outcome (Figure 11.6) is a tree nine steps longer than the most parsimonious; it is most unlikely Daka and the Koobi Fora hominins are phylogenetically closely related. 


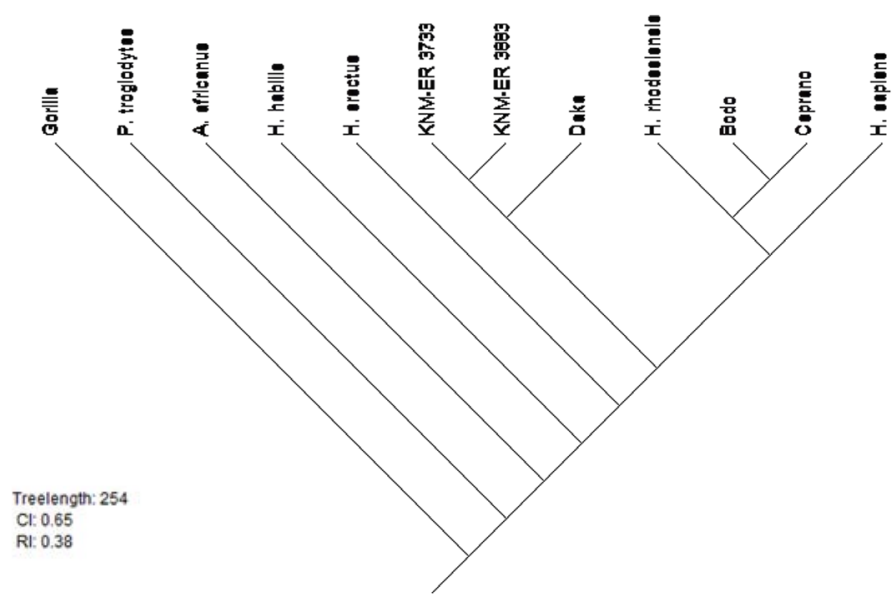

Figure 11.6: Daka and KNMs.

Source: Author's calculations.

\section{Ceprano}

Ceprano and $H$. erectus

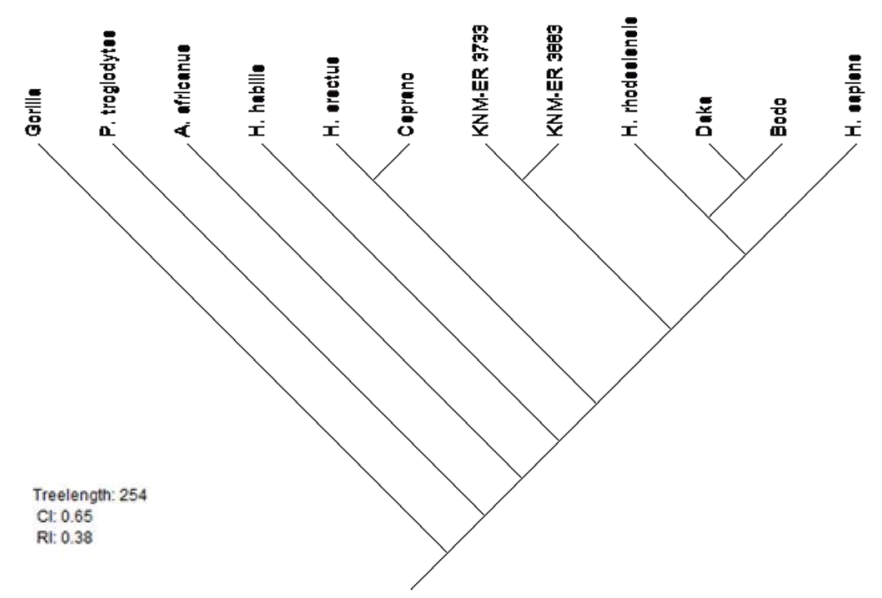

Figure 11.7: Ceprano and $H$. erectus.

Source: Author's calculations.

Ascenzi and others (2000) attributed Ceprano to $H$. erectus based upon a comparison of Ceprano's characteristics with a list of $H$. erectus characteristics 
compiled by Wood (1991). I tested for a possible phylogenetic relationship between Ceprano and $H$. erectus S.s., The shortest tree that includes the clade \{Ceprano, H. erectus\} is 254 steps (Figure 11.7), nine steps longer than the shortest tree $(\mathrm{L}=245)$; it is difficult to argue, then, that Ceprano shared an immediate common ancestor with Sangiran H. erectus.

\section{Buia}

Although Buia is unavailable for study, there is considerable published morphological information (Abbate et al., 1998; Macchiarelli et al., 2004). The cranium is estimated to date from $992 \mathrm{ka}$ (Albianelli and Napoleone, 2004) and is thus close in geological age to Daka (1.042 $\pm 0.009 \mathrm{Ma}$; Asfaw et al., 2002). Buia comprises a cranium, a large part of the facial skeleton, the base (Macchiarelli et al., 2004); and a left symphysis (Bondioli et al., 2006). Preliminary descriptions (Abbate et al., 1998; Macchiarelli et al., 2004) indicate that the braincase is very long $(204 \mathrm{~mm})$ compared to its width $(130 \mathrm{~mm})$, and is relatively high (Abbate et al., 1998).

Buia and Daka share many similarities. While the Buia cranium is longer than Daka (180 mm; Asfaw et al., 2002), both have an endocranial volume (ECV) of 995 cc (Daka: Asfaw et al., 2002; Buia: Macchiarelli et al., 2004). In lateral view the frontal profiles are rounded and rise relatively steeply from the supraorbital sulcus; the occipital profiles are rounded with an incipient bun. In frontal profile, both crania are widest inferiorly and have relatively straight-sided parietal walls but Buia's lateral walls converge inferiorly (Macchiarelli et al., 2004); reminiscent of Ceprano. Both Buia and Daka have reduced post-orbital constriction. The only section of the supraorbital available for Buia, the right lateral half, closely matches the form of the same region on Daka. There are, then, a number of phenetic similarities between these almost contemporaneous Homo that lived $600 \mathrm{~km}$ apart in the Danakil Depression, making it difficult to argue that they are from separate populations. A more detailed comparative analysis may show otherwise, of course, when Buia is available for study.

Buia and Ceprano also share a number of similarities: the parietals converge slightly inferiorly (Buia: Macchiarelli et al., 2004; Ceprano: Ascenzi et al., 1996: 419; pers. obs.); they have a small depression on the same area laterally on the front of the supraorbitals (Ceprano: pers. obs.; Buia: Macchiarelli et al., 2004, Fig 1); on both the frontals rise steeply; supraorbitals are interrupted at glabella (Buia: Macchiarelli et al., 2004); they have reduced post-orbital constriction; mastoid processes are short and broad; there are only modest external occipital protrusions, and slight angular tori. Ceprano has a slightly greater ECV, of $1185 \mathrm{cC}$ (72 cc larger than Buia and Daka). They differ, however, in that the temporal lines on Buia disappear early on the parietals, whereas Ceprano's temporal 
lines continue to asterion; Buia does not have an occipital torus (Macchiarelli et al., 2004), whereas Ceprano does; glabella is in a forward position on Buia (Macchiarelli et al., 2004), while this area is depressed on Ceprano; and Buia has an occipital 'bun' (Abbate et al., 1998, Figure 2b), which is absent on Ceprano.

\section{Discussion}

Identifying relationships between taxonomic units is of critical concern to the study of Homo. Cranial analyses were undertaken so that predictions could be made about the phylogenetic relationships between Early and Middle Pleistocene hominins Ceprano, Daka, Bodo and Kabwe.

Ceprano, Bodo, Daka and Kabwe form a supported branch in which Ceprano and Bodo appear to be the more derived taxa. Groves (1989) had also found Kabwe, Bodo and others fitted a common pattern and did not comprise a western variant of $H$. erectus; he attributed the group to $H$. sapiens heidelbergensis.

I hypothesise that Ceprano, Bodo, Daka and Kabwe form a species for which the prior available name is $H$. rhodesiensis (Smith Woodward, 1921). In this study $H$. rhodesiensis is characterised by an angulation between the pre-glenoid plane and the posterior slope of the articular tuberculum; a depression at glabella; a supraorbital margin that is thick, rounded and not demarcated from the roof of the orbit; a pre-glenoid plane anterior to the glenoid fossa; and a very prominent temporal band on the frontal.

While Buia was unavailable and could not be included in the cladistic analysis, a comparative assessment shows that it is very similar to Daka, and, to a slightly lesser extent, Ceprano. While I would propose from the discussion above that Buia is closely related to Daka at least, further analyses need to be undertaken when this cranium is fully described.

$H$. rhodesiensis thus composed is not closely related to $H$. erectus. $H$. erectus forms a separate lineage in the most parsimonious trees in which Daka, Ceprano and Bodo do not belong. Nor can Daka be shown to belong in the same species as the Koobi Fora hominins. 


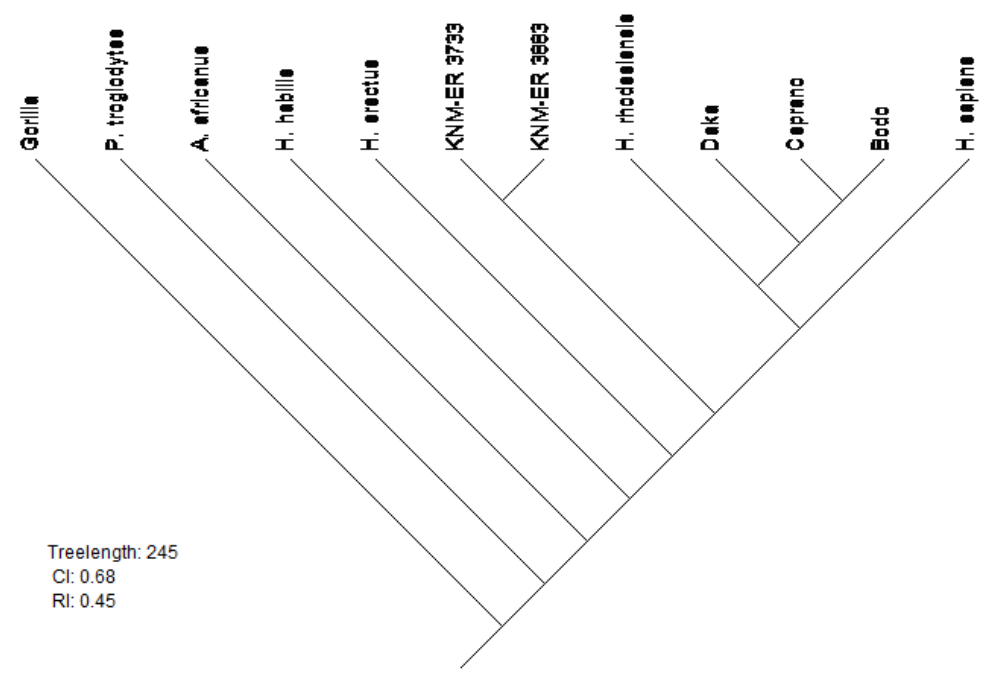

Figure 11.8: Preferred phylogeny.

Source: Author's calculations.

The key development in the evolution of the clade exemplified by Daka, Bodo, and Ceprano is a marked expansion of the vault, and, in Ceprano and Buia, the inferior contraction in the sides of the vault suggesting brain expansion during this period. Brain expansion in Homo is associated with a number of cranial characters: parietal bossing; high contour of the temporal squama; rounding of the occiput; and a relatively steeply sloping frontal (Rightmire, 1996). Kabwe has the first two of these characters, and a relatively large cranium with an ECV of 1300 cc (Holloway et al., 2004: 120). While Ceprano, Daka and Bodo differ in some aspects of cranial shape, they nevertheless represent an evolutionary shift in the overall form of the braincase, a shift we can also observe in Buia. Like Kabwe, vault walls are nearly parallel in Daka, but converge slightly inferiorly in Ceprano and Buia; and postorbital constriction is reduced in all. Ceprano and Daka are more derived than $H$. rhodesiensis in that their frontals rise more steeply, and they have rounded occipitals. Ceprano also has a relatively high temporal squama but does not have parietal bossing. Daka, too, lacks some of the characters associated with cranial expansion, such as a relatively high temporal squama. Although Bodo has a relatively large cranial capacity (1250 cc; Holloway et al., 2004) it does not show some of the other characters associated with an expanded braincase such as parietal bossing, greatest width at the parietals, or reduced post-orbital constriction, although its occipital seems to be rounded and it has a relatively high temporal squama contour. That is, although Bodo, Daka, and Ceprano all show marked cranial expansion in ECVs and related characters, none show all characters. 
Buia shares many characteristics with Daka and Ceprano and I hypothesise that there is a close phylogenetic relationship between them. Further, Buia and Daka are the same age and, arguably, the populations from which they came lived in geographical proximity.

\section{Conclusions}

The paradigm for human evolution in the late Early Pleistocene-Middle Pleistocene comprised a model in which one species, $H$. erectus, is present. As more hominin crania were discovered, for the most part they were placed in this species, requiring an ongoing broadening of the definition of $H$. erectus to accommodate the increasing variation in cranial morphology the newer discoveries presented. This is particularly so for the larger-brained crania Daka, Ceprano, and Bodo.

When these are assessed using cladistic analyses, in which sister-taxon relationships are sought, this group of hominins formed a supported branch that included $H$. rhodesiensis. This species shares a number of synapomorphies, but of equal importance is the evidence for expansion of the brain; and, for the first time, two hominins, Ceprano and Buia, show expansion at the parietals, rather than the prevailing condition in which crania are widest in a lower plane.

$H$. rhodesiensis is well separate from $H$. erectus in the phylogeny. Further, none of the target OTUs could be shown to have shared an immediate common ancestor with $H$. erectus.

The morphological variation in hominins during this period, then, is better explained by speciation than stasis; and the tendency to place new hominins within a framework comprising one species, $H$. erectus, is not supportable.

\section{References}

Abbate E, Albianelli A, Azzaroli A, Benvenuti M, Tesfamariam B, Bruni P, Cipriani N, Clarke RJ, Ficcarelli G, Macchiarelli R, Napoleone G, Papini M, Rook L, Sagri M, Tecle TM, Torre D, Villa I. 1998. A one-million-yearold Homo cranium from the Danakil (Afar) Depression of Eritrea. Nature 393:458-460.

Adefris T. 1992. A Description of the Bodo cranium: An archaic Homo sapiens cranium from Ethiopia. A dissertation in the Department of Anthropology, York University. Michigan, USA: UMI dissertation services. 
Albianelli A, Napoleone G. 2004. Magnetostratigraphy of the Homo-bearing Pleistocene Dandiero Basin (Danakil Depression, Eritrea). Riv Ital Paleontol S 110:35-44.

Argue D, Morwood M, Sutikna T, Jatmiko, Saptomo EW. 2009. Homo floresiensis: A cladistic analysis. J Hum Evol 57:623-629.

Argue D. 2010. The Genus Homo in the Early and Middle Pleistocene of Africa and Europe. PhD thesis, The Australian National University.

Ascenzi A, Biddittu I, Cassoli PF, Segre AG, Naldini E. 1996. A calvaria of late Homoerectus from Ceprano, Italy. J Hum Evol 31:409-423.

Ascenzi A, Mallegni F, Manzi G, Segre AG, Naldini ES. 2000. A re-appraisal of Ceprano calvaria affinities with Homo erectus, after the new reconstruction. J Hum Evol 39:443-450.

Asfaw B, Gilbert WH, Beyenne Y, Hart WK, Renne PR, Wolde G, Vrba ES, White TD. 2002. Remains of Homo erectus from Bouri, Middle Awash, Ethiopia. Nature 416:317-319.

Bermúdez de Castro JM, Arsuaga JL, Carbonell E, Rosas A, Martine I, Mosquera, M. 1997. A hominid from the Lower Pleistocene of Atapuerca, Spain: Possible ancestor to Neanderthals and modern humans. Science 276:1392-1395.

Bondioli L, Coppa A, Frayer DW, Libsekal Y, Rook L, Macchiarelli R. 2006. A one-million-year-old human pubic symphysis. J Hum Evol 50:479-483.

Bräuer, G. 1984. The Afro-European sapiens-hypothesis, and hominid evolution in Asia during the late Middle and Upper Pleistocene. In: Andrews, Franzen, JL. editors: The early evolution of man with special emphasis on Southeast Asia and Africa. Frankfurt am Main: Courier Forschungsinstitut Senckenberg. pp. 145-167.

Carpenter JM, Goloboff PA, Farris JS. 1998. PTP is meaningless, T-PTP is contradictory: A reply to Trueman. Cladistics 14:105-116.

Clarke JD, de Heinzelin J, Schlick KD, Hart WK, White D, Wolde Grabriel G, Walter RC, Suwa G, Asfaw B, Vrba E, H-Selassie Y. 1994. African Homo erectus: Old radiometric ages and young Oldowan assemblages in the Middle Awash Valley, Ethiopia. Nature 264:1907-1909.

Clarke RJ. 2000. A corrected reconstruction and interpretation of the Homo erectus calvaria from Ceprano, Italy. J Hum Evol 39:433-442.

Conroy GC, Jolly CJ, Cramer D, Kalb JE. 1976. Newly discovered fossil hominid skull from the Afar depression, Ethiopia. Nature 275:67-70. 
Taxonomic Tapestries

Faith DP, 1991. Cladistic permutation tests for monophyly and nonmonophylly. Syst Zool 40:266-375.

Faith DP, Cranston PS. 1991. Could a cladogram this short have arisen by chance alone? On permutation tests for cladistic structure. Cladistics 7:1-28.

Falguèrès C, Bahain J-J, Yokoyama Y, Arsuaga JL, de Castro BJM, Carbonell E, Bischoff JL, Dolo J-M. 1999. Earliest humans in Europe: The age of TD6 Gran Dolina, Atapuerca, Spain. J Hum Evol 37:343-352.

Fu J, Murphy RW. 1999. Discriminating and locating character covariance: An application of Permutation Tail Probability (PTP) analysis. Syst Biol 48(2):380-385.

Grimaud, D. 1982. Évolution du parietal de l'Homme fossile, position de l'Homme de Tautavel parmi les hominidés. Thése de 3éme cycle. Muséum National d'Histoire Naturelle (indet).

Groves CP. 1989. A theory of human and primate evolution. Oxford: Clarendon Press.

Hennig W. 1966. Phylogenetic systematics. Urbana, Chicago: University of Illinois Press.

Hillis D, Bull JJ. 1993. An empirical test of bootstrapping as a method for assessing confidence in phylogenetic analysis. Syst Biol 42(2):182-192.

Holloway RL, Broadfield DC, Yuan MS. 2004. The human fossil record, Volume 3. Brain endocasts - the paleoneurological evidence. Somerset, NJ: John Wiley and Sons. pp. 129.

Hrdlicka A. 1930. The skeletal remains of early man. Washington: Smithsonian Institution.

Hublin JJ. 1978. Le torus occipital transverse et les structures associées: Evolution dans le genre Homo. Thése de 3éme cycle, Université P. and M. Curie, Paris IV (inédet).

Humphries CJ. 2002. Homology, characters and continuous variables. In: MacLeod N, Forey PL, editors. Morphology, shape and phylogeny. Systematics Association Special Volume Series 64. London and New York: Taylor and Francis. pp. 8-27.

Kalb J, Jolly CJ, Mebrate A, Tebedge S, Smart CM, Oswald EB, Cramer D, Whitehead P, Wood CB, Conroy GC, Adefris T, Sperling I, Kana B. 1982. Fossil mammals and artefacts from the Middle Awash Valley, Ethiopia. Nature 298:25-29. 
Källersjö M, Farris JS, Kluge AG, Bult C. 1992. Cladistics: What's in a word? Cladistics 9:183-199.

Lahr MM. 1996. The evolution of modern human diversity: A study on cranial variation. Cambridge: Cambridge University Press.

Macchiarelli R, Bondioli M, Chech M, Coppa A, Fiore I, Russom R, Vecchi F, Libsekal Y, Rook L. 2004. The late Early Pleistocene human remains from Buia, Danakil Depression, Eritrea. In: Abbate E, Woldehaimanot B, Libsekal Y, Tecle TM, Rook L, editors. A step towards human origins. The Buia Homo one million years ago in the Eritrean Danakil Depression (East Africa). Riv Ital Paleontol S 110 Supplement:133-144.

MacIntosh NWG, Larnach SL. 1972. The persistence of Homo erectus traits in Australian Aboriginal crania. Archaeology and Physical Anthropology in Oceania 7:1-7.

Maddison WP, Maddison DR. 1992. MacClade: Analysis of phylogeny and character evolution. Version 3.0. Sunderland, Massachusetts: Sinauer Associates.

Mallegni F, Carnieri E, Bisconti M, Tartarelli G, Ricci S, Biddittu I, Segre A. 2003. Homo cepranensis sp nov and the evolution of African-European Middle Pleistocene hominids. Comptes Rendus Palevol 2:153-159.

Manzi G, Bruner E, Passarello P. 2003. The one-million-year-old Homo cranium from Bouri (Ethiopia): A reconsideration of its $H$. erectus affinities. J Hum Evol 44:731-736.

Manzi G, Magri DB, Salvatore M, Palombo MR, Margari V, Celiberti V, Barbieri M, Barbieri, Mu, Melis RT, Rubini M, Ruffo M, Saracino B, Tzedakis PC, Zarattin A, Biddittu I. 2010. The new chronology of the Ceprano calvarium (Italy). J Hum Evol 59:580-585.

Manzi G, Mallegni F, Ascenzi A. 2001. A cranium for the earliest Europeans: Phylogenetic position of the hominid from Ceprano, Italy. Proc Natl Acad Sci 98:10011-10016.

Mbua E, Bräuer G. 2012. Patterns of Middle Pleistocene hominin evolution in Africa and the emergence of modern humans. In: Reynolds S, Gallagher A, editors. African genesis: Perspectives on hominin evolution. Cambridge: Cambridge University Press. pp. 366-422.

Muttoni G, Scardia G, Kent DV, Swisher Carl C, Manzi G. 2009. Pleistocene magnetochronology of early hominin sites at Ceprano and Fontana Ranuccio, Italy. Earth Planet Sci Lett 286:255-268. 
Taxonomic Tapestries

Nomade S, Muttoni G, Guillou G, Robin E, Scardia G. 2011. First 40Ar/39Ar age of the Ceprano man (central Italy). Quaternary Geology 6(5):453-457.

Rightmire GP. 1976. Relationships of Middle and Upper Pleistocene hominids from sub-Saharan Africa. Nature 260:238-240.

Rightmire GP. 1996. The human cranium from Bodo, Ethiopia: Evidence of speciation in the Middle Pleistocene? J Hum Evol 31:21-39.

Sartono S., Grimaud, D. 1983. Les parétaux des Pithécanthropines Sangiran 12 et Sangiran 17. L'Anthropologie 87:475-482.

Schwartz JH, Tattersall I. 2002. The human fossil record: Craniodental morphology of Genus Homo. Volume 2: Africa and Asia. New York: Wiley Liss.

Stringer CB. 1984. The definition of Homo erectus and the existence of the species in Africa and Europe. In: Andrews P, Franzen JL, editors. The early evolution of man with special emphasis on Southeast Asia and Africa. Frankfurt am Main: Courier Forschungsinstitut Senckenberg. pp. 131-143.

Smith Woodward A. 1921. A new cave man from Rhodesia, South Africa. Nature $17: 371-372$.

Swofford D. 2002. PAUP* Version 4.0b10. Distributed by Sinauer Associates, Inc. Smithsonian Institute.

Trueman JWH. 1993. Randomization confounded: A response to Carpenter. Cladistics 9:101-109.

Weidenreich F. 1943. The Skull of Sinanthropus Pekinensus. Palaeontologia Sinica. Pehpei, Chungking. Oxford: Geological Survey of China. pp. 270-272.

Wiley EO, Lieberman BS. 2011. Phylogenetics. theory and practice of phylogenetic systematics. Hoboken, NJ: John Wiley and Sons, Inc. pp. 90-193.

Wood B. 1991. Koobi fora research project, vol. 4: Hominid cranial remains. Clarendon Press, Oxford.

Zeitoun V. 2000. Revision of the species Homo erectus (Dubois, 1893). Use of morphologic and metric data in cladistic investigation of the case of Homo erectus. B Mem Soc Anthro Par 12:1-200. 


\section{Appendix 1. Character states}

\section{1. continuity of post orbital sulcus}

$0=$ absent because of continuity of frontal and supraorbital

$1=$ present but incomplete, interrupted in the medial zone

$2=$ present - complete and with a distinct edge or border

\section{2. postorbital lateral depression}

(a depression on the lateral supraorbital region bounded by the temporal line)

$0=$ absent

$1=$ present

3. depression at glabella in norma facialis

$0=\mathrm{absent}$

$1=$ present

4. shape of frontal edge in norma verticalis

$0=$ linear

$1=$ convex frontwards

5. position of glabella in norma verticalis

$0=$ glabella zone is depressed

$1=$ glabella is neither depressed or protruding

2 = glabella projects beyond the frontal

6. continuity of the supraorbital torus

$0=$ no supraorbital torus

1 = incomplete, interrupted in the medial zone - there are 2 distict tori 'monoorbitares'

$2=$ continuous torus

7. superior surface of orbit margins

$0=$ flow smoothly into frontal squama

$1=$ horizontal posttoral plane from which squama rises posteriorly

$2=$ there is a sulcus between posterior aspect of elevated supraorbital rim and frontal squama 
Taxonomic Tapestries

8. type of orbital arcade - supraorbitals

Where ' $a$ ' is central, ' $b$ ' is middle and ' $c$ ' is lateral:

$0=a>b, b<c$ and $a<c$

$\mathrm{l}=\mathrm{a}>\mathrm{b}, \mathrm{b}<\mathrm{c}$ and $\mathrm{a}>\mathrm{c}$

$2=\mathrm{a}<\mathrm{b}, \mathrm{b}>\mathrm{c}$ and $\mathrm{a}>\mathrm{c}$

$3=a>b, b>c$ and $a>c$

$4=$ no variation in form

The objective is to determine differences in superior-inferior height of supraorbital across the orbit. Measurements were used to determine ' $a$ ', ' $b$ ', 'c' for each specimen.

9. prominence of temporal line on the frontal

$0=$ weak

$1=$ very prominent

10. metopic keeling

$0=\mathrm{absent}$

$1=$ present but weak

$2=$ strong

11. development of the keeling

$0=$ parallel edges

$1=$ wider and flatter posteriorly

$2=$ absent (no keeling)

12. bregmatic eminence

$0=$ absent

$1=$ present

13. upper coronal reinforcement

$0=\mathrm{absent}$

$1=$ present

\section{4. frontal bosse}

$0=$ absent

$1=$ present 
15. obelionic region

$0=$ keeling present

$1=$ no keeling

$2=$ presence of obelionic depression

16. pre-lambdaic depression

$0=$ keeling on 4 th quarter

$1=$ no keeling on 4 th quarter

$2=$ present

17. presence of the temporal band after the coronal suture

$0=$ absent

$1=$ present

18. asterionic process

$0=$ absent

$1=$ present

19. parietal bosse

$0=$ absent

$1=$ present

20. angular tuber

$0=\mathrm{absent}$

$1=$ present

21. curvature of nuchal plane in norma lateralis

$0=$ convex posteriorly

1 = flat to lightly concave posteriorly

22. importance of the occipital torus

$0=$ weak

$1=$ strong

$2=$ no occipital torus

23. extension of external occipital protrusion

$0=$ absent

$1=$ present 
Taxonomic Tapestries

\section{4. extension of the tuberculum linearum}

This refers to the degree of elevation, or relief, at the junction of the superior nuchal line and occipital crest.

$0=$ absent

$1=$ moderate

$2=$ strong

25. medial concavity of the occipital lip to the tuberculum linearum

Is there a depression above where nuchal lines meet?

$0=$ absent

$1=$ depression

26. external occipital crest, where present

$0=a b s e n t$

$1=$ present for whole of nuchal

$2=$ present above inferior nuchal line

$3=$ present below inferior nuchal line

27. occipitomastoid crest

$0=$ absent

$1=$ present

28. height of temporal squama cf vault

$0=$ high

$1=$ low

29. shape of the temporal squama

$0=$ polygon to round

$1=$ triangular

30. strength of supramastoid crest in the region of porion

$0=$ weak

$1=$ strong

31. relation between the supramastoid crest and zygomatic process in lateral view

$0=$ zygomatica forms an angle with supramastoid crest

$1=$ zygomatica is continuous with supramastoid crest 
32. continuity of the supramastoid crest with the inferior temporal line

$0=$ no direct link

$1=$ continuity

33. tuberculum supramastoid anterius

Is there a tubercle where supramastoid crest stops at squamous suture?

$0=$ absent

$1=$ present

34. strength of the mastoid crest

$0=$ weak

$1=$ strong

35. continuity between mastoid crest and superior temporal line

$0=$ no direct link

$1=$ continuity

36. supramastoid sulcus, where present

$0=$ closed posteriorly

$1=$ open posteriorly

37. importance of supramastoid sulcus

$0=$ absent

$1=$ narrow

$2=$ wide

38. convergence of mastoid crest and supramastoid crest

$0=$ divergent anteriorly

$1=$ parallel

39. suprameatum spine

$0=$ absent

$1=$ present

40. section of tympanal in norma lateralis

$0=$ rounded

$1=$ ellipsoid to ovoid 
Taxonomic Tapestries

41. orientation of main axis of tympanal in norma lateralis

$0=$ orientated anteriorly

$1=$ vertical

$2=$ orientated posteriorly

42. thickness of tympanic in norma lateralis (anterior edge of tympanic)

$0=$ weak

$1=\operatorname{strong}(>2 \mathrm{~mm})$

43. contribution of the tympanal to mandibular fossa

$0=$ postglenoid process is strongly involved in the wall

$1=$ the tympanal makes up most of the wall

$2=$ rudimentary or no postglenoid process

44. relative development of mastoid process in norma lateralis

(i.e. does it project below the base of the cranium?)

$0=$ does not project below the base of the cranium

$1=$ projects below base

45. extension of the pre-glenoid planum

(Is there a level surface of bone preceding the mandibular fossa from the articular eminence either for the whole, or at least half, of the width of the eminence?)

$0=$ no pre-glenoid planum precedes the glenoid cavity

$1=$ a pre-glenoid planum precedes the glenoid cavity

46. space between the tympanal and anterior of mastoid process

$0=$ posterior part of tympanal joins anterior part of mastoid process

$1=$ 'split'

2 = wide space

47. anteroposterior width of mandibular fossa

$0=$ narrow

$1=$ wide

48. deepness of glenoid fossa

$0=$ very shallow

$1=$ deep 
49. height of articular eminence relative to posterior wall of glenoid fossa (basal view)

$0=$ slope is shorter

$1=$ similar

2 = higher

50. orientation of mastoid process

$0=$ not orientated inwards

$1=$ orientated inwards

51. deepness of digastric fossa

$1=$ shallow

$2=$ deep

52. size of juxtamastoid eminence

$0=$ no eminence

$1=$ weak

$2=$ strong

53. importance of deepness between entoglenoid formation and tympanic plate

$0=$ fused

1 = groove

$2=$ space

54. anterior wall of glenoid fossa

$0=$ the anterior wall is horizontal

$1=$ oblique

$2=$ almost vertical

55. inferior projection of the entoglenoid process compared to that of the tuberculum zygomaticum anterior

$1=$ entoglenoid projects to a greater extent than the tuberculum zygomaticum anterior

$2=$ entoglenoid is similar to tuberculum zygomaticum anterior in degree of inferior projection

$3=$ entoglenoid is less projected than the tuberculum zygomaticum anterior 
56. relative position of the entoglenoid formation to the tuberculum zygomaticum anterior

$0=$ the entoglenoid formation is at the same level as the tuberculum zygomaticum

$1=$ the entoglenoid formation is posterior to the tuberculum zygomaticum

$2=$ entoglenoid formation is very posterior to the tuberculum zygomaticum

57. inferior projection of the entoglenoid process and the tuberculum zygomaticum compared to the tuberculum articulare

$0=$ very large inferior projection relative to the tuberculum articulare

$1=$ large inferior projection relative to the tuberculum articulare

$2=$ small inferior projection relative to the tuberculum articulare

58. antero-posterior convexity of the tuberculum articular (articular eminence)

$0=$ the tuberculum articular is flat in norma lateralis

$1=$ the tuberculum articular forms a large round arc

$2=$ the tuberculum articular forms a small round arc

59. shape of posterior edge of the tuberculum articular in norma basilaris

$0=$ flat

$1=$ arched

$2=$ sigmoid

60. continuity between the pre-glenoid planum and the posterior slope of the articular tuberclum

$0=$ the two are continuous

$1=$ there is an angulation between them

61. crest on lateral edge of mandibular fossa

$0=$ absent

$1=$ present

62. inferior projection of entoglenoid process compared to the sphenoid border/edge

$0=$ the entoglenoid process projects inferiorly to a greater extent than sphenoid edge

$1=$ the entoglenoid process is equivalent in inferior projection to sphenoid edge $2=$ the entoglenoid process is les projected than sphenoid edge 
63. prominence of entoglenoid formation

$0=$ very prominent

$1=$ not prominent

64. lateral extension of entoglenoid process

$0=$ very extended posteriorly

$1=$ marginally extended backward

$2=$ not extended posteriorly

$3=$ tubercle

$4=$ not extended posteriorly or tubercle

65. does postglenoid process extend out beyond tympanic?

$0=$ doesn't overlap the tympana

$1=$ does overlap the tympana

$2=$ no postglenoid process or rudimentary process

66. profile of nasal saddle and nasal roof

1 = flat nasal bones

2 = slightly raised nasals, forming a curve

3 = nasals forming well-defined curve, ranging in size from medium to large

$4=$ deep angled nasal bones forming a 'pinched nose'

67. relationship of rhinion to nasospinale

$1=$ nasospinale lies in front of rhinion

$2=$ nasospinale is on same plane as rhinion

$3=$ nasospinale lies behind rhinion

68. condition of the margo limitans

$1=$ the margo limitans forms a sill

$2=$ margo limitans forms a smooth curve

$3=$ margo limitans includes a prenasal groove

69. the condition of the facies anterior of maxilla and alveolar process

$1=$ the facies anterior and alveolar process is inflated,

$2=$ the facies anterior and alveolar process is well filled out

$3=$ the facies anterior and alveolar process is sunken

$4=$ the facies anterior and alveolar process forms a flat surface 
Taxonomic Tapestries

70. presence of jugum alveolar

$1=$ there is no jugum alveolar

$2=$ the jugum alveolar forms a narrow ridge

$3=$ the jugum alveolar forms a broad and prominent ridge (width of $1+$ premolar)

71. presence of a sulcus infraorbitalis (i.e. under the infraorbital foramen)

$1=$ there is no sulcus infraorbitalis

$2=$ the sulcus infraorbitalis is narrow

$3=$ the sulcus infraorbitalis is wide

72. zygomaticoalveolar crest (ordered)

$1=$ relatively straight

$2=$ curved

$3=$ forms an arc

4 = forms an arch

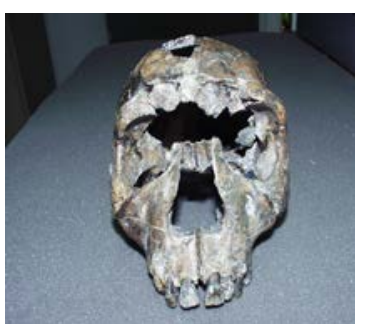

State 2 (curved)

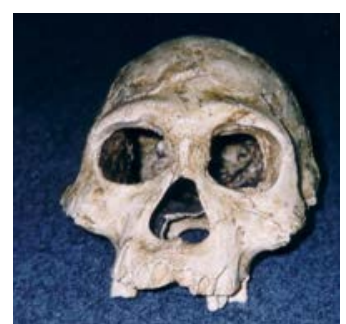

State $3(\operatorname{arc})$

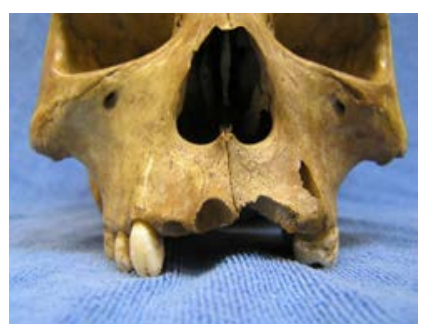

State 4 (arch)

Description: KNM-WT 15000 frontal view 102

Description: D2700 caste frontal view

Description: P1221728

73. shape of naso-alveolar clivus

$1=$ naso-alveolar clivus is convex

$2=$ naso-alveolar clivus is flat

$3=$ naso-alveolar clivus is concave

74. palate surface has low irregular crests or fine ridges arranged in more or less longitudinal direction

$1=$ present

$2=\mathrm{absent}$ 


\section{5. location and direction of orifice of incisive canal}

$1=$ orifice of incisive canal is immediately posterior to incisors

$2=$ orifice of incisive canal is on a plane with canines

$3=$ orifice of incisive canal is on a plane with 1st premolar

$4=$ orifice of incisive canal is on a plane with 2 nd premolar

\section{6. location of zygomatic arch}

$1=$ the zygomatic arch runs below the Frankfurt horizontal

$2=$ the zygomatic arch runs at level of Frankfurt horizontal

$3=$ the zygomatic arch runs above the Frankfurt horizontal

\section{7. condition of the supraorbital margin}

$1=$ the supraorbital margin is thick, rounded and not demarcated from roof of orbit $2=$ the margin is thick with an edged crest not demarcated from roof of orbit $3=$ the supraorbital margin is an edged crest demarcated from the roof of orbit $4=$ the supraorbital margin is thin with an edged crest and demarcated from the roof of orbit

\section{8. condition of infraorbital margin of the orbits}

$1=$ sharp high line dividing the floor of the orbit from the facial portion of the malar $2=$ relatively rounded orbital margin but raised in relation to floor of the orbit 3 = pronounced rounding of the inferior lateral border which is leveled with the floor of the orbit (i.e. lower outside edge for half the lower edge of orbit is rounded but other half of lower orbit not rounded)

\section{9. character of superior fissure}

$1=$ the superior fissure is small and round

$2=$ superior fissure is a slit-like lateral prolongation

$3=$ there is a strut dividing the fissure into 2

80. styloid process

$1=$ present

$2=$ absent

\section{1. tympanic trough}

A coronally oriented long narrow trough along tympanic tube in basal view

$0=$ absent

$1=$ present 
Taxonomic Tapestries

82. sagittal keeling on first half of parietal.

$0=$ absent

$1=$ present

83. presence of external occipital crest

$0=\mathrm{absent}$

$1=$ present

84. presence of glasseri fissure

$0=$ absent

$1=$ present

85. supraorbital torus

$0=\mathrm{absent}$

$1=$ present

86. tuberculum linearum

$0=$ absent

$1=$ present

87. maximum cranial breadth

$0=$ at supramastoid region

$1=$ at parietal region

88. length of nuchal dominates over length of occipital

Determined by comparing measurement for lambda-inion (occipital length) and measurement for inion-opisthion (nuchal length)

$0=$ yes

$1=$ no

89. foramen magnum

$0=$ round

$1=$ oval 
This text is taken from Taxonomic Tapestries: The Threads of Evolutionary, Behavioural and Conservation Research, edited by Alison M Behie and Marc F Oxenham, published 2015 by ANU Press, The Australian National University, Canberra, Australia. 